\title{
Mechanism Switch in Mannich-type Reactions. ELF and NCI Topological Analyses of the Reaction between Nitrones and Lithium Enolates
}

\author{
David Roca-López, ${ }^{[a]}$ Victor Polo,${ }^{[b]}$ Tomás Tejero, ${ }^{[a]}$ and Pedro Merino*[a]
}

\begin{abstract}
The mechanism of the addition of lithium enolates derived from esters, ketones and aldehydes to nitrones (Mannich-type reaction) has been studied using DFT methods. While the reactions with a-methoxy and a-methyl enolates takes place through a stepwise mechanism, consisting of an initial nucleophilic attack of the enolate to the nitrone carbon followed by a second nucleophilic attack of the nitrone oxygen to the formed carbonyl group, the reaction with $\alpha$-unsusbtituted enolates takes place through a onestep mechanism. The IRC analysis shows the presence of a hidden intermediate in agreement with one kinetic step two stages process. The topological analysis of the electronic localization function (ELF) confirms that only when the first $\mathrm{C}-\mathrm{C}$ bond is formed, does the $\mathrm{C}-\mathrm{O}$ bond formation begin. The $\mathrm{NCl}$ analyses, are also in agreement with the formation of intermediates for $\alpha$-methoxy and $\alpha$-methyl enolates and a highly asynchronous one-step process in the case of $\alpha$ unsusbtituted enolates.
\end{abstract}

\section{Introduction}

Mannich-type reactions are probably the most popular approach for the synthesis of $\beta$-amino carbonyl compounds. ${ }^{[1]}$ The direct addition of enolates to a variety of functionalities including imines $^{[2]}$ as well as other $\mathrm{C}=\mathrm{N}$ groups such as nitrones, hydrazones and iminium salts ${ }^{[3]}$ is especially useful to create different types of $\beta$-nitrogenated carbonyl derivatives in a single synthetic operation. In particular, the use of nitrones as substrates has received considerable attention because they lead to $\beta$-aminocarbonyl functionalities in which the nitrogen group is at an intermediate oxidation state (Scheme 1). The final product can be a $\beta$-hydroxyamino carbonyl derivative or the corresponding isoxazolidin-2-one obtained after an intramolecular cyclization. In addition, the Mannich-type reaction of nitrones has provided access to enantiomerically pure compounds of biological and pharmacological interest including aminosugars, ${ }^{[4]}$ iminosugars, ${ }^{[5]}$ nucleoside analogues, ${ }^{[6]}$

[a] D. Roca-López, Prof. T. Tejero and Prof. P. Merino

Laboratorio de Síntesis Asimétrica. Departamento de Síntesis Estructura de Biomoléculas. Instituto de Síntesis Química y Catálisis Homogénea (ISQCH). Universidad de Zaragoza. CSIC. Campus San Francisco. E-50009 Zaragoza. Aragón, Spain.

E-mail: pmerino@unizar.es

[b] Dr. V. Polo

Departamento de Química Física and Instituto de Biocomputación y Física de Sistemas Complejos (BIFI). Universidad de Zaragoza. Campus San Francisco. E-50009 Zaragoza. Aragón, Spain.

Supporting information for this article is given via a link at the end of the document.

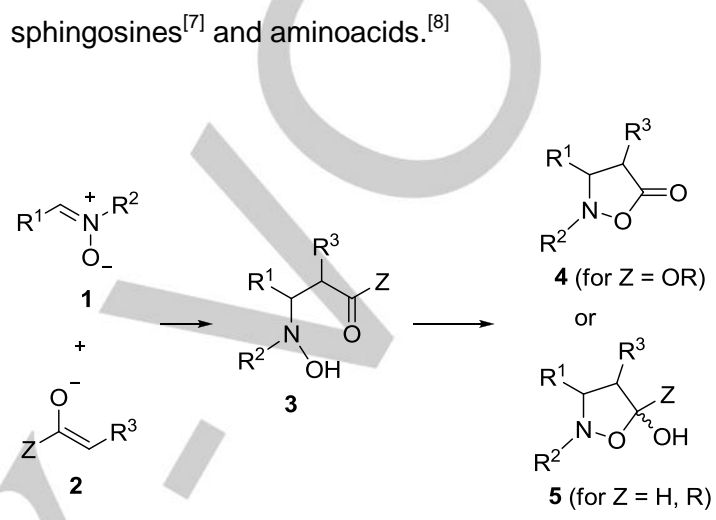

Scheme 1. Mannich-type reactions of nitrones

Several nucleophiles can be used in the reaction, ${ }^{[9]}$ the most commonly employed being enolates derived from esters in the form of lithium, ${ }^{[6 a]}$ sodium, ${ }^{[6 a]}$ boron ${ }^{[8 b, 10]}$ and titanium salts. ${ }^{[8 b, 10-11]}$ Silyl enolates derived from esters (silyl ketene acetals) have also extensively used in the presence of Lewis acids. $\left.{ }^{[4 b, 6 b, c} 8 c, e, 12\right]$ Recently, enol silanes formed in situ, derived from ketones, amides and thioesters have been reported to add to nitrones in the presence of trialkylsilyl trifluoromethane-sulfonates. ${ }^{[13]}$ On the contrary, there are only two examples regarding the reaction between nitrones and metal enolates derived from ketones ${ }^{[14]}$ and a self-catalyzed Mannich-type reaction between nitrones and 1,3-dicarbonyl compounds (without any base) has been recently reported. ${ }^{[15]}$ To the best of our knowledge, no previous reports on the reaction with metal enolates derived from aldehydes are documented.

From a mechanistic point of view, the addition of silyl ketene acetals to nitrones presented some controversy since the reaction was initially postulated to take place through a stepwise mechanism ${ }^{[8 c, 16]}$ whereas a concerted mechanism involving a pentacoordinated silicon was also invoked on the basis of semiempirical calculations. ${ }^{[8]}$ On the other hand, a different semiempirical study pointed out that the mechanism of the reaction could change from concerted to stepwise depending on the Lewis acid used as activating agent. ${ }^{[17]}$ Further DFT calculations with very simple models in gas phase and without considering Lewis acids (which are required for the advance of the reaction) presented the reaction like a typical concerted inverse-demand 1,3-dipolar cycloaddition. ${ }^{[18]}$ Finally, consideration of a more realistic scenario taking into account both the presence of Lewis acids and solvent effects confirmed that both concerted and stepwise mechanisms are competitive. ${ }^{[19]}$ 
Experimental and theoretical investigations have demonstrated that the reactions of organometallic reagents, such as organolithium ${ }^{[19-20]}$ and Grignard ${ }^{[21]}$ derivatives, with nitrones take place through the initial formation of a complex SC (Scheme 2). When the nucleophile is a lithium enolate (usually derived from an ester) the final product of the reaction is an isoxazolidine. This heterocycle could be formed from the initial complex SC through either a concerted mechanism (Scheme 2, A) or a typical nucleophilic addition stepwise mechanism (Scheme 2, B). During past investigations we confirmed the stepwise mechanism for $\alpha$-methoxyenolates derived from esters $(\mathrm{Z}=\mathrm{OR}){ }^{[19,20 \mathrm{c}]}$ In that case, the stepwise mechanism is favored because of the stabilization of the developing positive charge in TS-B1 by the Z=OR group. However, it remains unstudied the case of lithium enolates derived from aldehydes and ketones (Scheme $2, \mathrm{Z}=\mathrm{H}, \mathrm{R}$ ) in which such stabilization is not present and the concerted mechanism could be an option.

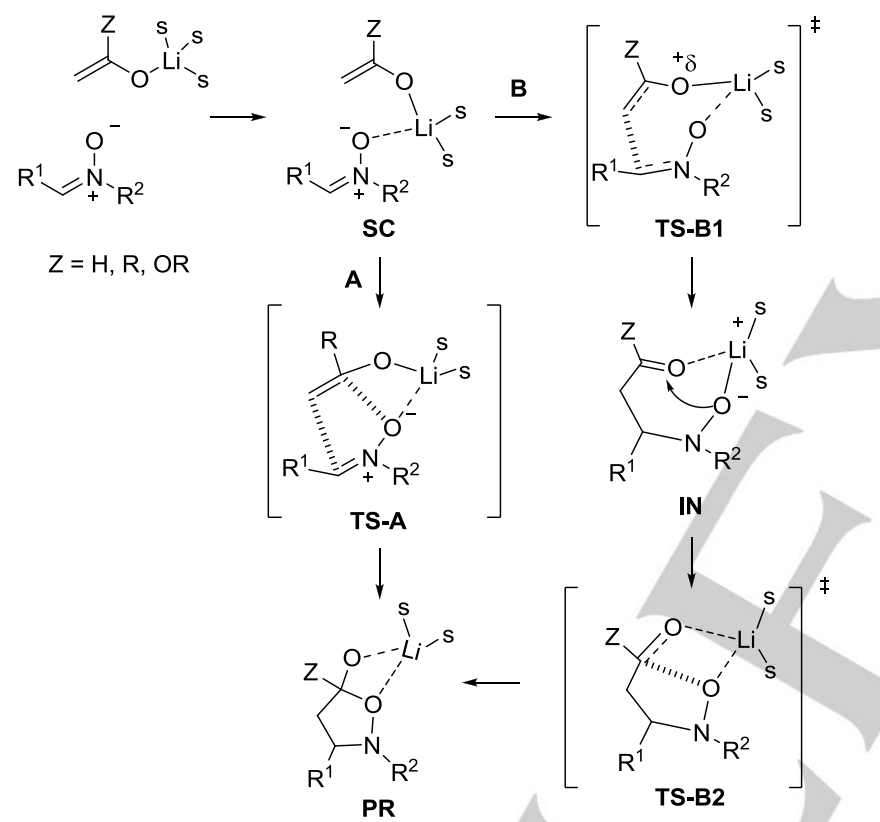

Scheme 2. One-step (A) and stepwise (B) mechanisms for the addition of lithium enolates to nitrones.

Despite the apparent similarity between lithium enolates derived from aldehydes, ketones and esters all these species are rather different if we consider their electronic properties, ${ }^{[22]}$ which are crucial for the stability of postulated intermediates. In order to shed some light on the preferred pathways (concerted or stepwise) it is necessary a full theoretical study considering in detail all the possible paths. Herein, we report a DFT study on the reaction of lithium enolates derived from esters, ketones aldehydes. The study includes a detailed analysis of all points of the intrinsic reaction coordinates (IRCs) by using $\mathrm{NCl}$ and ELF topological analyses that will allow discerning the concertedness of each process.

\section{Computational Methods}

All of the calculations were performed using the Gaussian09 program. ${ }^{[23]}$ Molecular geometries were optimized with the M062X functional ${ }^{[24]}$ in conjunction with cc-pVTZ basis set. ${ }^{[25]}$ Truhlar and co-workers reported that for examining barrier heights, a minimally augmented basis set like the Dunning cc-pVTZ is appropriate. ${ }^{[26]}$ It was not necessary to augment the pTZV basis with extra diffuse functions, as tests carried out by using aug-ccpVTZ basis, resulted in changes in the relative energies of less than $1 \mathrm{kcal} / \mathrm{mol}$ while making calculations considerably more time-consuming. Moreover, the use of M06-2X in conjunction with cc-pVTZ basis has provided excellent results in related calculations with nitrones. ${ }^{[27]}$ We can therefore expect that the computed values should be sufficiently reliable to be able to draw meaningful conclusions. Analytical second derivatives of the energy were calculated to classify the nature of every stationary point, to determine the harmonic vibrational frequencies, and to provide zero-point vibrational energy corrections. The thermal and entropic contributions to the free energies were also obtained from the vibrational frequency calculations, using the unscaled frequencies. All transition structures were characterized by one imaginary frequency and were confirmed to connect to reactants and products by intrinsic reaction coordinate (IRC) calculations. ${ }^{[28]}$ The IRC paths were traced using the second order González-Schlegel integration method. ${ }^{[29]}$ Solvent effects were calculated using the continuum solvation model $(\mathrm{PCM})^{[30]}$ using a dielectric constant of 7.4257 to simulate THF, and microsolvation of the lithium atom was considered by explicit inclusion of dimethyl ether ligands (to reduce computational cost we replace discrete THF molecules by dimethyl ether units) to complete the coordination sphere of lithium, according to previous reports by Domingo and coworkers. ${ }^{[31]} \mathrm{A}$ four-fold (tetrahedral) coordination sphere was chosen for the lithium atom in agreement with previous studies. ${ }^{[32]} \mathrm{NCl}$ (non-covalent interactions) were computed using the methodology previously described. ${ }^{[3]}$ Data were obtained with the NCIPLOT program. ${ }^{[34]}$ A density cutoff of $\rho=0.1$ a.u. was applied and the pictures were created for an isosurface value of $\mathrm{S}=0.4$ and colored in the $[-0.02,0.02]$ a.u. $\operatorname{sign}\left(\lambda_{2}\right) \rho$ range using VMD software. ${ }^{[35]}$ The electronic structures of stationary points were analyzed by the topological analysis of the gradient field of electron localization function $(E L F)^{[36]}$ developed by Silvi and Savin. ${ }^{[37]}$ The ELF study was performed with the TopMod program $^{[38]}$ using the corresponding monodeterminantal wavefunctions of the all structures of the IRC. The topological analysis of the gradient field of ELF has showed to be a powerful tool for the study of the bonding changes along an organic reaction. ${ }^{[39]}$ Advantages and drawbacks of $\mathrm{NCl}$ index, compared with $\mathrm{ELF}^{[40]}$ and QTAIM (quantum theory of atoms in molecules) ${ }^{[41]}$ have been reported. Structural representations were generated using CYLView. ${ }^{[42]}$ Animation given in the supporting material was created by extracting and processing all points of the IRC with an in-house program and saving the corresponding images to create an animated GIF. The lithium enolate derived from methyl acetate (ENa, $Z=O M e)$, the actual reagent employed in previous experimental reports, ${ }^{[20 \mathrm{c}, 43]}$ was 
used in the calculations. For the purpose of comparison and in order to study the only differences exerted by diverse groups vicinal to the carbonyl function, the corresponding enolates derived from acetone $(\mathrm{ENb}, \mathrm{Z}=\mathrm{Me}$ ) and acetaldehyde (ENc, $\mathrm{Z}$ $=\mathrm{H})$ were chosen as models. To reduce computational cost, the model nitrone NI maintaining the fundamental characters of a real $\mathrm{N}$-substituted (Z)-nitrone (the preferred configuration for aldonitrones), has been chosen.

\section{Results and Discussion}

Mechanistic study. Even though a lithium enolate can be expressed as ROLi, its composition in a real solution is far more complex. In polar solvents like THF (and in the absence of chelating agents) lithium enolates are cubic tetramers, ${ }^{[44]}$ although in some cases dimers can be formed and, in the presence of additives, monomers can also be present. ${ }^{[45]} \mathrm{A}$ computational study carried out with the lithium enolate derived from acetaldehyde demonstrated that monomeric species is important in the equilibrium due to its high solvation energies, ${ }^{[46]}$ although more recent calculations showed that tetramer is the major species in THF, monomeric species being preferred in the presence of chelating agents. ${ }^{[47]}$ Additional computational studies reported that modeling by coordination to dimethyl ether and dielectric solvation reduces considerably the exothermicity of the aggregation. ${ }^{[48]}$ An experimental study with the lithium enolate of $\alpha$-phenylcyclohexanone demonstrated that an equilibrium exists between the monomer and the dimer, the former being more reactive in alkylation reactions. ${ }^{[49]}$ Thus, it is reasonable to assume that, with independence of the structural type of the lithium enolate in solution, the nitrone can break the aggregates (in a similar way to the reactions with Grignard reagents ${ }^{[50]}$ ) and form an initial complex SC as considered for other reactions. ${ }^{[48]}$

We consider six different approaches, leading to the corresponding transition structures, between nitrone $\mathbf{N I}$ and monomeric enolates ENa, ENb and ENc, corresponding to three staggered orientations and two different faces of the enolate (Scheme 3). From these six approaches only three of them, leading to $\mathbf{a}, \mathbf{b}$, and $\mathbf{c}$ series allow the preferred coordination of both reagents to the lithium atom. Thus, for those leading to $\mathbf{d}, \mathbf{e}$ and $\mathbf{f}$ series, corresponding to a direct approach without formation of an initial complex, an additional molecule of solvent has been added to complete a fourfold coordination sphere for lithium. ${ }^{[51]}$

We first revisited the mechanism of the nucleophilic addition of a-methoxyenolate ENa to nitrone NI. In our previous report ${ }^{[19]}$ we considered IN (Scheme 2), formed from complex SC through TS-B1, as the final product of the reaction. However, the reaction can continue through two alternative diastereomeric channels to form cyclic cis and trans products PR which evolve to the isoxazolidin-2-one $\mathbf{4}$ observed experimentally (Scheme 4). $[6 \mathrm{a}, 20 \mathrm{c}, 52]$

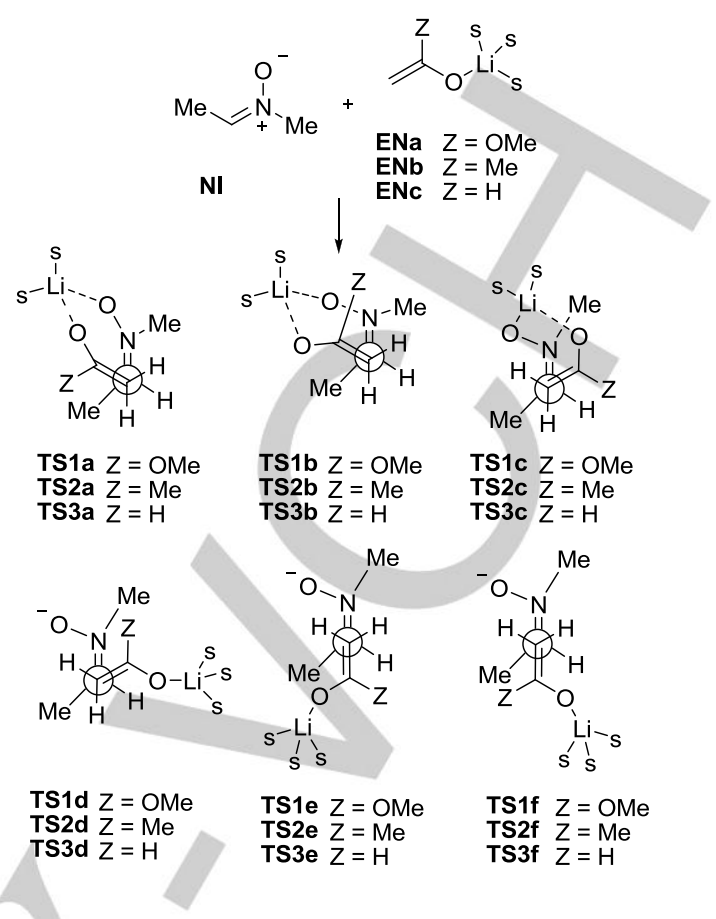

Scheme 3. Approaches between nitrone NI and enolates ENa-c.

Formally, the reaction between $\mathbf{N I}$ and ENa to form P1a and $\mathbf{P} 1 \mathbf{b}$ can be considered a [3+2] cycloaddition. The analysis of the potential energy surface showed the direct approach higher in energy and thus the corresponding transition structures TS1d, TS1e and TS1f were not further considered (Figure 1). On the other hand, formation of a complex $\mathbf{C} 1$ resulted in a stabilization of $4.2 \mathrm{kcal} / \mathrm{mol}$. Starting from $\mathbf{C} 1$ the three transition states TS1a, TS1b and TS1c, corresponding to the formation of a C-C bond between the most nucleophile center of the enolate ENa (the unsubstituted methylene) and the most electrophilic center of the nitrone NI (the azomethine carbon) through the two faces of the enolate, were located. The complete mechanism is given in Scheme 4 while the energy profile for the reaction and main geometrical features of stationary points corresponding to the formation of $\mathbf{P} \mathbf{1 a}$ and $\mathbf{P} \mathbf{1} \mathbf{b}$ are given in Figure 1.

The IRC analyses confirmed $\mathbf{C} \mathbf{1}$ as the starting point for the three transition structures, and IN1b as the final point for both TS1b and TS1c; for TS1a in which the addition of the nitrone takes place by the other face of the enolate IN1a was identified as the final point. The most stable transition state corresponds to TS1a with an energy barrier of $6.4 \mathrm{kcal} / \mathrm{mol}$ whereas TS1b and TS1c present barriers of 7.2 and 8.5 $\mathrm{kcal} / \mathrm{mol}$, respectively. According to a classical Boltzmann distribution analysis, TS1a accounts for $80 \%$ of all the transition structures but in terms of the mechanism it is irrelevant because all the approaches are stepwise. 


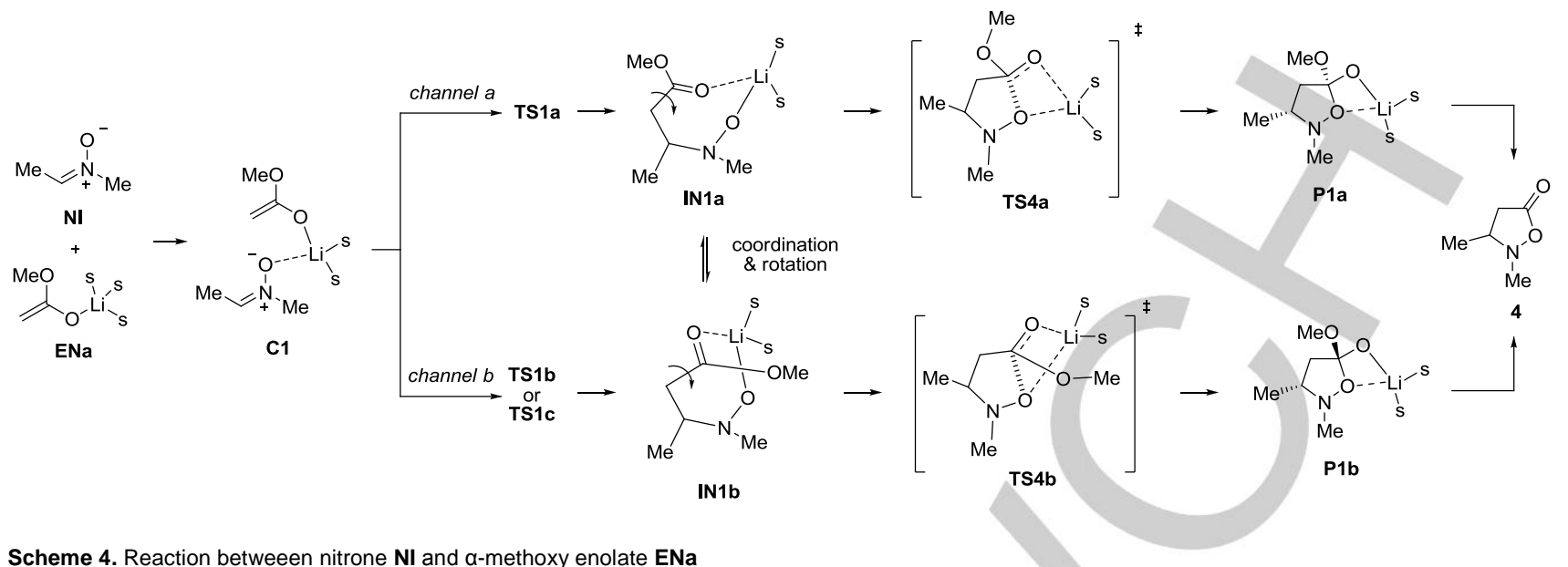

Scheme 4. Reaction betweeen nitrone NI and a-methoxy enolate ENa
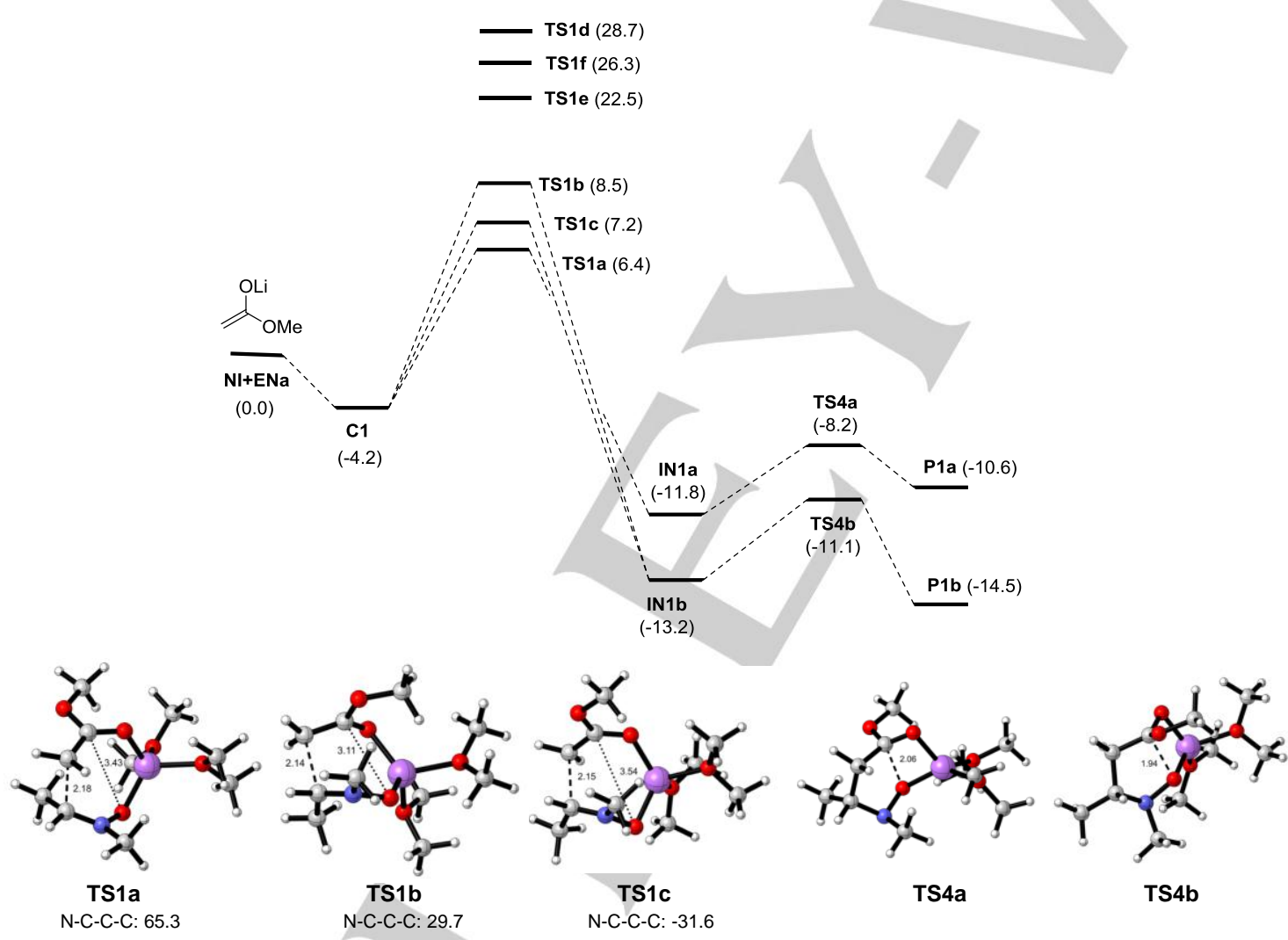

Figure 1. Energy diagram (M06-2X/cc-pVTZ/PCM=THF) and stationary points for the reaction between nitrone $\mathrm{NI}$ and $\alpha$-methoxy enolate ENa. Relative free energy values $\left(\Delta \mathrm{G}_{298}\right)$ are given in $\mathrm{kcal} / \mathrm{mol}$.

The distances of the forming bond in TS1a, TS1b and TS1c are $2.18,2.14$ and $2.15 \AA$, respectively, whereas the distances between the nitrone oxygen and the enolate carbon linked to the two oxygen atoms are $3.43,3.11$ and $3.54 \AA$ for TS1a, TS1b and TS1c, respectively thus confirming the absence of a close interaction between the two reactive centers. Consequently, the reaction is a typical nucleophilic addition. Indeed, any attempt of locating concerted transition structures in which the formation of the two bonds could take place in a concerted (although asynchronous) manner, failed. The stability of IN1a and IN1b was confirmed after the corresponding optimizations which showed them to be 11.8 and $13.2 \mathrm{kcal} / \mathrm{mol}$ below the ground state, respectively. Both intermediates could also interconvert through a process of decoordination of the lithium atom and rotation of the ester moiety. The formation of IN1a and IN1b is followed by the intramolecular attack of the hydroxyamino group 
to the ester carbonyl, via the planar four-membered ring transition states TS4a and TS4b, leading eventually to the lithium coordinated orthoesters $\mathbf{P} \mathbf{1 a}$ and $\mathbf{P} \mathbf{1 b}$, respectively. The forming $\mathrm{C}-\mathrm{O}$ bond lengths in TS4a and TS4b are $2.06 \AA$ and $1.94 \AA$, respectively and in both cases the IRC analysis showed IN1a and IN1b as the starting points. Also, in both TS4a and TS4b the forming isoxazolidine ring adopts an envelope conformation. The channel $b$ is favored over the channel a since the nucleophilic attack of the oxygen atom to the ester carbonyl in the latter is found to be sterically better positioned.

The whole processes are exergonic by $10.6 \mathrm{kcal} / \mathrm{mol}$ for channel $a$ and $14.5 \mathrm{kcal} / \mathrm{mol}$ for channel $b$. As a result, whereas channel $a$ is kinetically preferred because TS1a, at the ratedetermining step, is the most stable, channel $b$ is more favorable thermodinamically. However, the selectivity cannot be experimentally observed because after quenching the reaction the corresponding orthoesters eliminate the methoxy group to give isoxazolidine-2-one 4 . We have not studied computationally the final step leading to $\mathbf{4}$ because it has no relevance in the mechanism of the addition reaction. Thus, in the case of $\alpha-$ methoxyenolates the stability of intermediates IN1a and IN1b is ultimately responsible for the process to be stepwise. Indeed, in some similar cases it has been observed experimentally ${ }^{[53]}$ the obtention of free hydroxylamine directly derived from those complexes.

In the case of ketone enolate $\mathbf{E N b}$, calculations also establish that the direct approach, in which only $\mathbf{E N b}$ is coordinated to lithium, are prohibitively high in energy, with energy barriers of $30.2,24.4$ and $29.8 \mathrm{kcal} / \mathrm{mol}$ for TS2d, TS2e and TS2f, respectively. On the other hand, starting from complex C2, located at $4.2 \mathrm{kcal} / \mathrm{mol}$ below the ground state, energy barriers of $8.3,9.9$ and $11.7 \mathrm{kcal} / \mathrm{mol}$ were found for
TS2a, TS2c and TS2b, respectively (Scheme 5, Figure 2). The geometrical features as well as the energy profile are given in Figure 2.

The IRC analysis for TS2a and TS2c (both attacking by the same face of the enolate) confirmed intermediates IN2a and IN2b as the final points of the reaction. However, the same analysis for TS2b (corresponding to the attack for a different face of the enolate) indicated the process as concerted, the product P2a being the final point. The geometries of transition structures TS2a-c $(R=M e$, Scheme 5$)$ are similar to the corresponding partners TS1a-c (Scheme 4) but the electronic features are different. In the case of TS1b, the presence of the methoxy group contributes to stabilize the developing partial positive charge at the carbonyl carbon atom; the $\mathrm{C}-\mathrm{O}$ distance of $3.11 \AA$ indicates that electrostatic interaction is not enough for causing the collapse of the second forming bond. Under these circumstances the intermediate IN1b is enough stable to exist. On the other hand, in TS2b the methyl group is not capable of stabilizing the above mentioned partial positive charge and, consequently, the electrostatic interaction between carbon and oxygen atoms is stronger (as revealed by a shorter $\mathrm{C}-\mathrm{O}$ distance of $3.05 \AA$ ). In this scenario the $\mathrm{C}-\mathrm{O}$ interaction collapses to a bond and the reaction takes place in one single kinetic step. This sort of spontaneous downhill process is well known and it has also been observed by other authors. ${ }^{[54]}$ The endo orientation of the methyl group causes unfavorable steric interactions that explain the higher energy of TS2 $\mathbf{b}$ with respect to TS2a and TS2c. As in the case of $\alpha$-methoxyenolate, the formation of IN2a and IN2b is followed by an intramolecular attack through TS5a and TS5b leading to orthoesters $\mathbf{P} \mathbf{2} \mathbf{a}$ and $\mathbf{P} \mathbf{2 b}$, respectively (Scheme 5, R = Me).

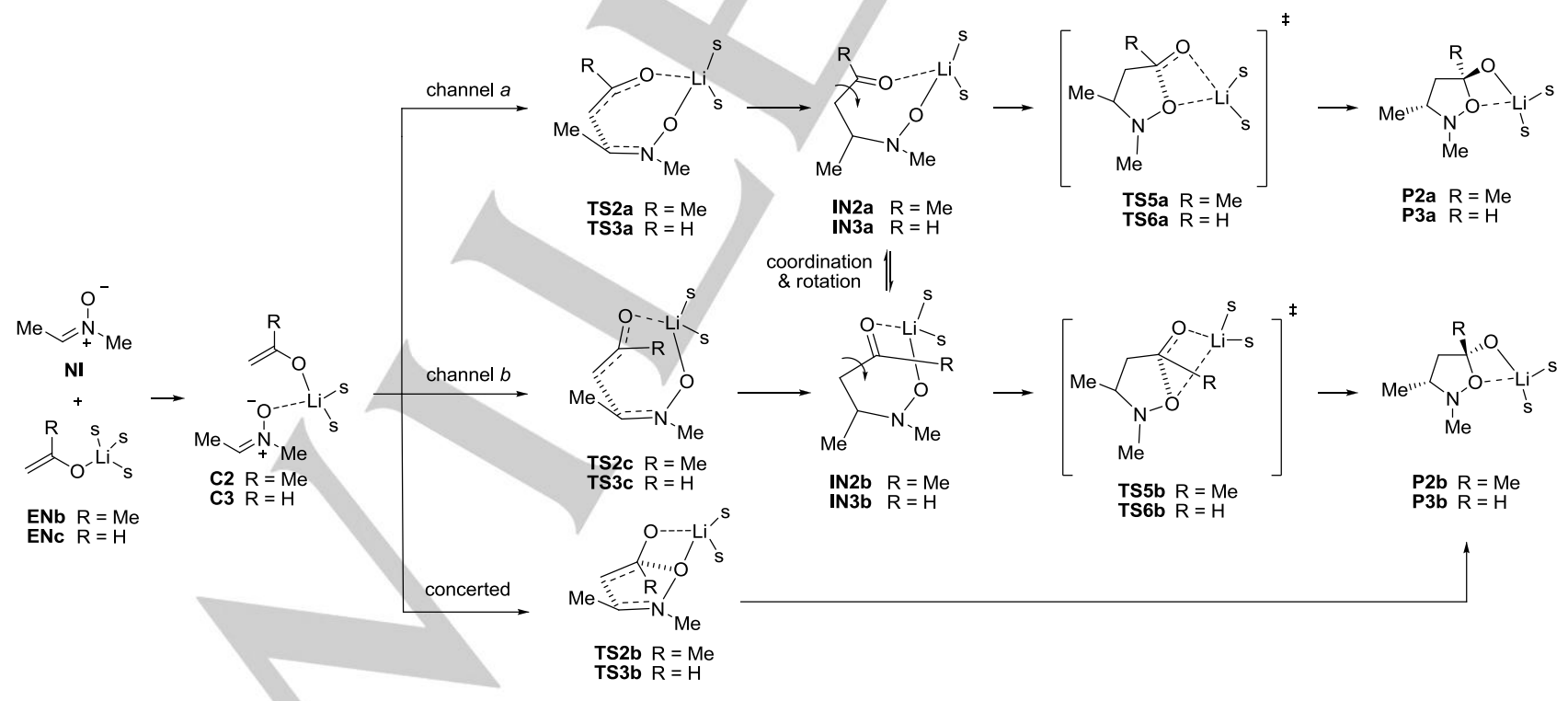

Scheme 5. Reaction betweeen nitrone NI and enolates ENb,c 


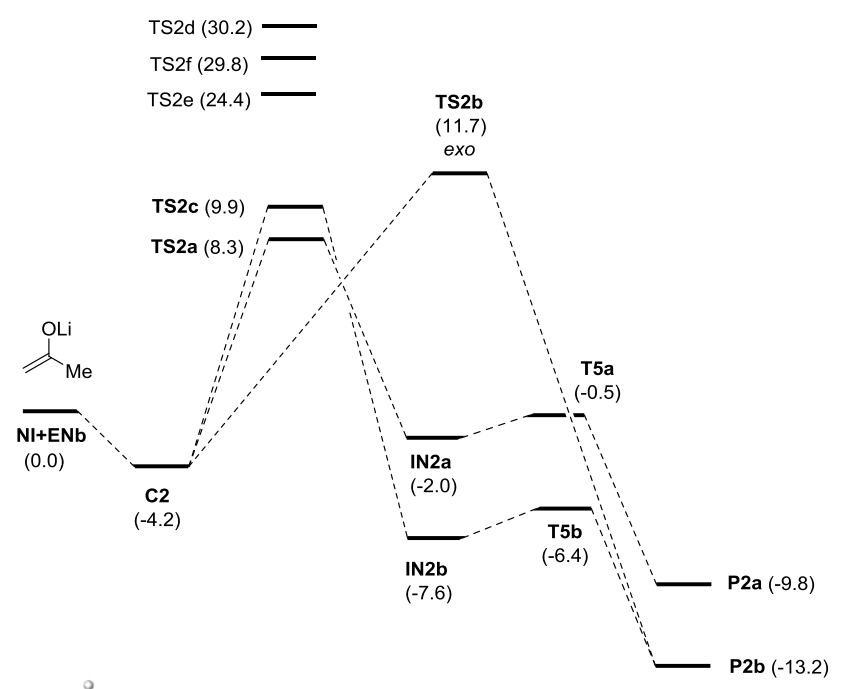

reaction between nitrone $\mathrm{NI}$ and a-methyl enolate ENb takes place through a stepwise mechanism with a barrier of 8.3 $\mathrm{kcal} / \mathrm{mol}$ at the rate-limiting step.

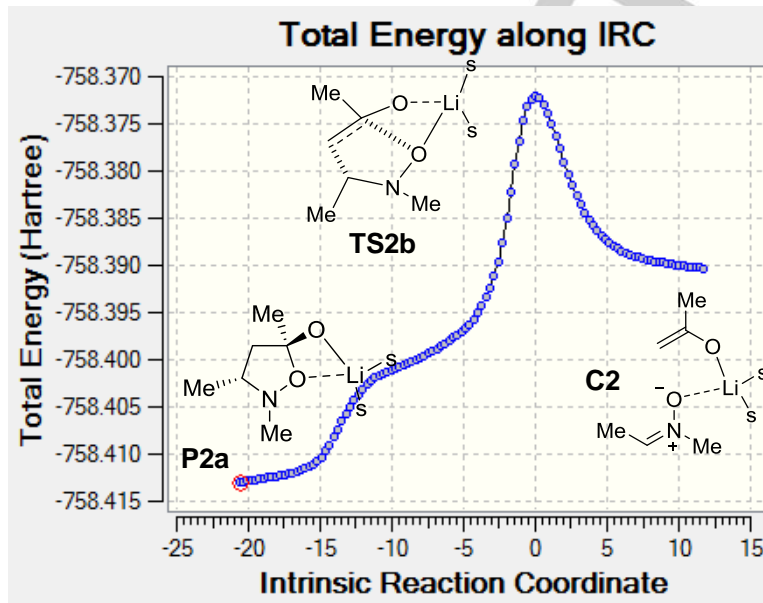

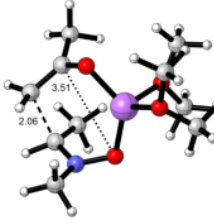

TS2a N-C-C-C: 75.7

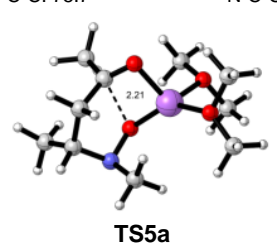

TS2c
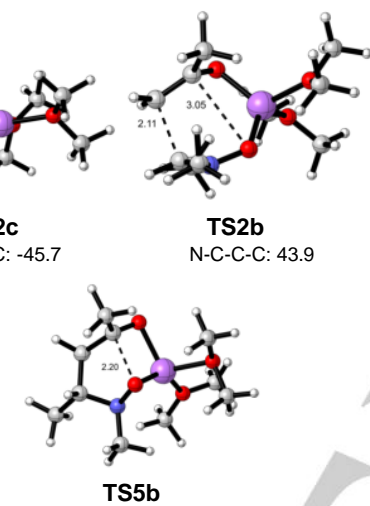

Figure 2. Energy diagram (M06-2X/cc-pVTZ/PCM=THF) and stationary points for the reaction betweeen nitrone $\mathrm{NI}$ and $\alpha$-methoxy enolate $\mathbf{E N b}$. Relative free energy values $\left(\Delta \mathrm{G}_{298}\right)$ are given in $\mathrm{kcal} / \mathrm{mol}$.

Notably, the IRC analysis of the concerted pathway showed a shoulder revealing the presence of a so-called hidden intermediate (Figure 3). ${ }^{[55]}$ According to this analysis and the excessively long forming $\mathrm{C}-\mathrm{O}$ bond $(3.05 \AA$ ) , only when the transition state is passed and the C-C bond is formed, does the formation of the second $\mathrm{C}-\mathrm{O}$ bond start. This process consisting in two consecutive chemical events (formation of C-C and C-O bonds) is in agreement with a typical one-step-two-stages reaction according to Domingo and co-workers ${ }^{[39 b]}$ and similar to that observed for the reaction between nitrones and lithium ynolates. ${ }^{[27 b]}$ Indeed, on going from TS2b to cycloadduct $\mathbf{P 2} \mathbf{b}$, through IRC, intermediate structures (see below the ELF analysis) have the $\mathrm{C}-\mathrm{C}$ bond already formed whereas the $\mathrm{C}-\mathrm{O}$ bond formation is very delayed. However, steric reasons due to the inside orientation of the methyl group make TS2b higher in energy and we can conclude that this path is not preferred for this reaction. The Boltzmann distribution analysis predicted that TS2a, corresponding to the stepwise process, accounts for almost $95 \%$ of all the transition structures while TS2b, corresponding to the one-step process, accounts for only $5 \%$. Consequently, despite the presence of the concerted path, the

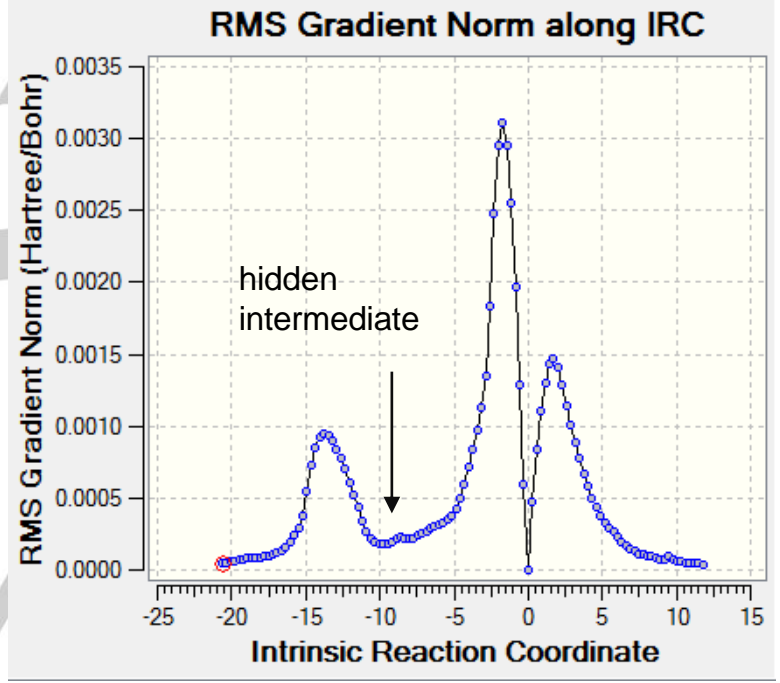

Figure 3. Computed (M06-2X/cc-pVTZ/PCM=THF) backwards intrinsic reaction coordinate (IRC) for the reaction between nitrone $\mathbf{N I}$ and enolate $\mathbf{E N b}$ showing the relative energy (top) and the gradient norm showing a prominent hidden intermediate (bottom)

A similar situation accounts in the reaction between nitrone $\mathbf{N I}$ and enolate ENc. Again, the three transition structures corresponding to the direct approach present very high energy barriers $(30.8,27.9$ and 29. $2 \mathrm{kcal} / \mathrm{mol}$ for TS3d, TS3e and TS3f, respectively). The free energy barriers for lithium-coordinated transition structures TS3a, TS3b and TS3c are calculated to be 12.3, 10.5 and $12.1 \mathrm{kcal} / \mathrm{mol}$, respectively. The geometrical features as well as the energy profile are given in Figure 4.

As observed for a-methyl enolate, TS3b appeared as a highly asynchronous transition structure with a long $\mathrm{C}-\mathrm{O}$ forming bond $(2.99 \AA)$ in comparison with the C-C forming bond $(2.10 \AA)$. The IRC calculation confirmed the concertedness of the reaction revealing no intermediates between TS3b and P3b. However, contrary to a-methyl enolate, transition state TS3b, 
corresponding to the one-step process, showed to be the most stable (by $1.6 \mathrm{kcal} / \mathrm{mol}$ ) confirming a change of mechanism from enolate ENb to enolate ENc. In fact, the Boltzmann distribution analysis indicated in this case that TS3b accounts for almost 92\% of all the transition structures while TS3a and TS3c, corresponding to stepwise processes, account for ca. $3 \%$ and $5 \%$, respectively. The steric contact of the $N$-methyl group is more unfavorable for the methyl group (TS2b) than for the hydrogen atom (TS3b), thus predicting a lower barrier for the $\alpha$ unsubstituted enolate ENc (Figure 4). The unfavorable formation of IN3a and IN3b is followed by an intramolecular attack through TS6a and TS6b leading to orthoesters P3a and P3b, respectively (Scheme $5, R=H$ ). The IRC calculation for the concerted process show similar features to those observed in the case of $a$-methyl enolate for TS2b. It confirms that $\mathbf{C} 3$ and P3a are connected by TS3b without intermediates but a hidden intermediate is also present (Figure 5). Thus, in the case of the a-unsusbstituted enolate ENc, the reaction takes place preferentially along a concerted two-stage one-step mechanism with an energy barrier of $10.5 \mathrm{kcal} / \mathrm{mol}$.
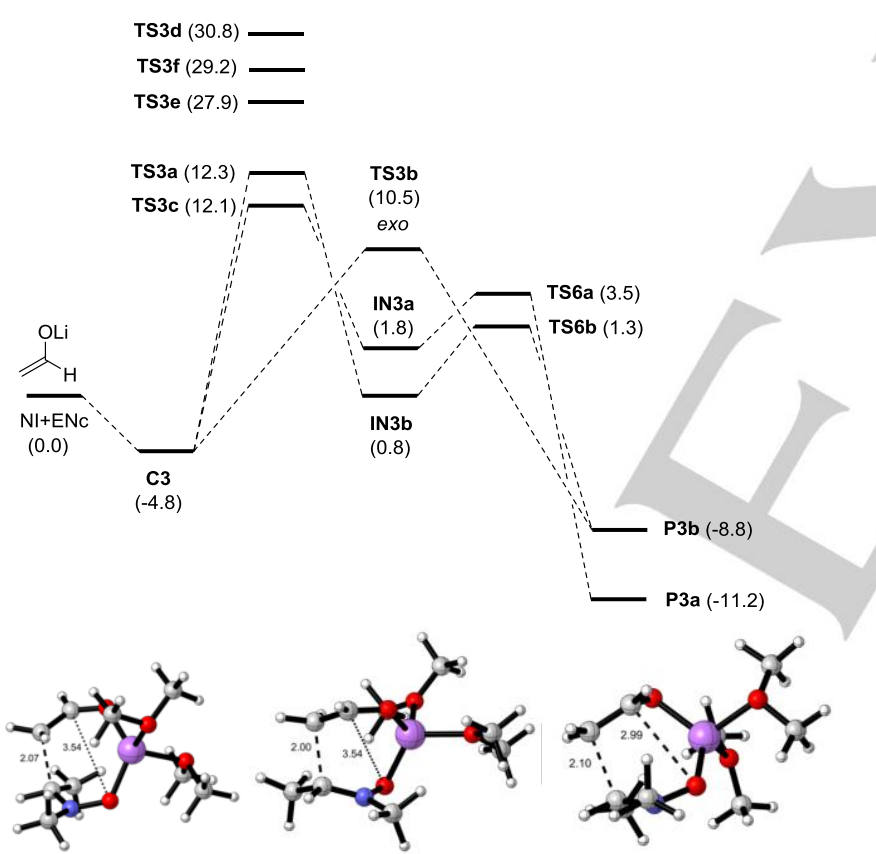

TS3b

N-C-C-C: 101.0

TS3c -C-C-C: 45
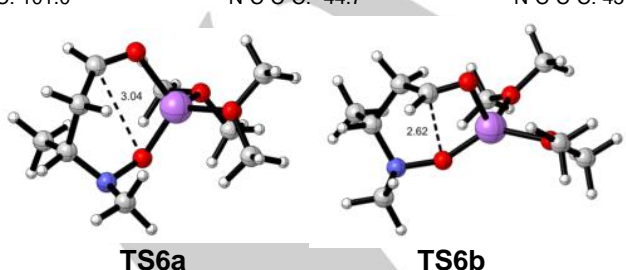

Figure 4. Energy diagram (M06-2X/cc-pVTZ/PCM=THF) and stationary points for the reaction betweeen nitrone $\mathbf{N I}$ and $\alpha$-methoxy enolate ENc. Relative free energy values $\left(\Delta \mathrm{G}_{298}\right)$ are given in $\mathrm{kcal} / \mathrm{mol}$.
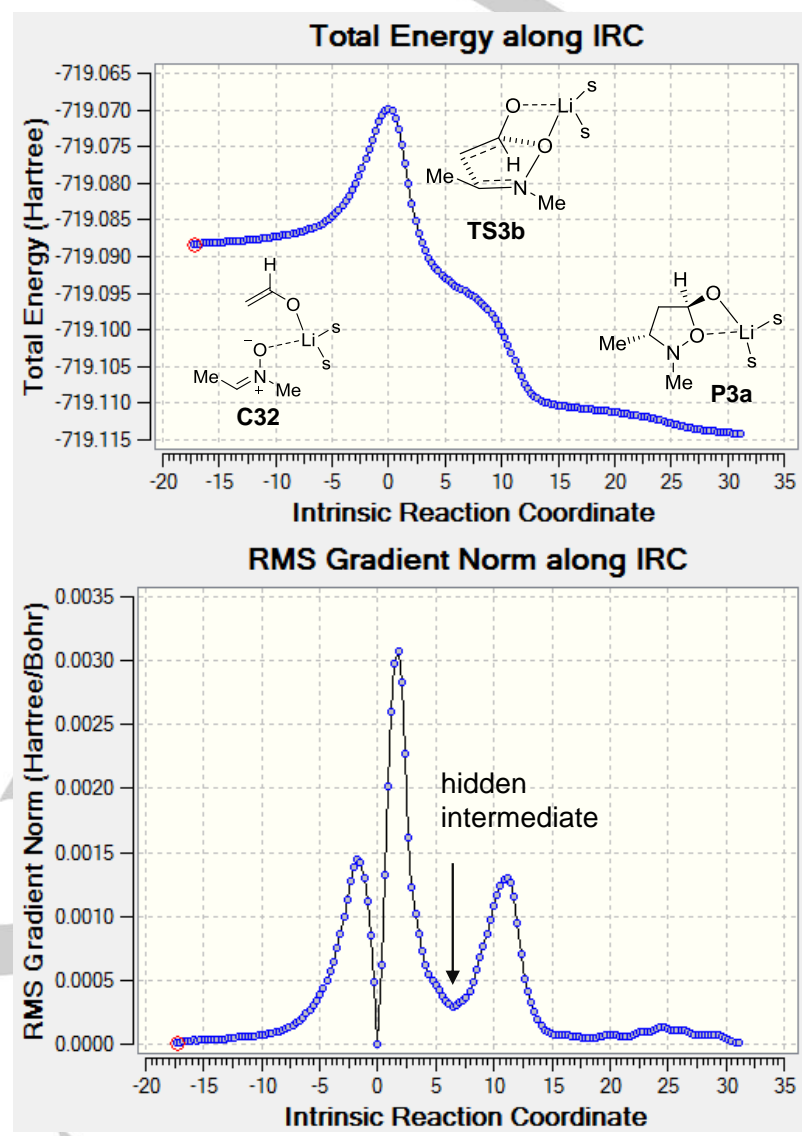

Figure 5. Computed (M06-2X/cc-pVTZ/PCM=THF) intrinsic reaction coordinate (IRC) for the reaction between nitrone $\mathbf{N I}$ and enolate ENc showing the relative energy (top) and the gradient norm showing a prominent hidden intermediate (bottom).

$\mathrm{NCl}$ and ELF analyses. The topological analysis of ELF has recently demonstrated to be of great utility in analyzing $\mathrm{C}-\mathrm{C}$ bond formation in a variety of non-polar, polar and ionic organic reactions. ${ }^{[56]}$ The $\mathrm{NCl}$ analysis ${ }^{[33]}$ has also demonstrated their utility in the analysis of several reactions ${ }^{[55 b, 57]}$ including nucleophilic additions to $\mathrm{C}=\mathrm{N}$ bonds. ${ }^{[58]}$ We have carried out the complete ELF and $\mathrm{NCl}$ analyses for the IRCs corresponding to the most stable paths of the addition reactions of enolates ENac to nitrone NI (For animations showing movies of the reactions illustrating both ELF and $\mathrm{NCl}$ analyses see supporting material). The numbering used for the analyses is illustrated in Figure 6. ELF basin populations of selected points on the IRC including initial and final points, transition structures, intermediates and points indicating bond formation are given in the supporting information. 


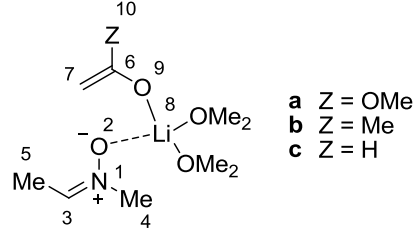

Figure 6. Numbering used for ELF and $\mathrm{NCl}$ analyses.

In the case of the reaction between $\mathbf{N I}$ and ENa leading to TS1, the double $\mathrm{C} 3=\mathrm{N} 1$ bond is transformed into the single C3-N1 bond, the double $\mathrm{C} 6=\mathrm{C} 7$ bond is transformed into the single $\mathrm{C} 6$ $\mathrm{C} 7$ bond and the $\mathrm{C} 3-\mathrm{C} 7$ bond is created. The ELF descriptors corresponding to this step are presented in Figure 7. The two disynaptic basins associated to the $\mathrm{C} 3=\mathrm{N} 1$ and $\mathrm{C} 6=\mathrm{C} 7$ double bonds are merged, in TS1a (point 58 of the IRC), each other to become one indicating the transformation of the doble bonds into single one; in fact the electronic populations decreased slightly for both $\mathrm{C} 3-\mathrm{N} 1$ and $\mathrm{C} 6-\mathrm{C} 7$ bonds. The decreasing of the electronic population of $\mathrm{C} 3-\mathrm{N} 1$ and $\mathrm{C} 6-\mathrm{C} 7$ bonds continues during $\mathrm{C} 3-\mathrm{C} 7$ bond formation (points 55 and 54 of the first IRC) and simultaneously a monosynaptic basin appeared at C7. At point $55(\mathrm{~d}(\mathrm{C} 3, \mathrm{C} 7)=2.04 \AA ; \mathrm{d}(\mathrm{C} 6, \mathrm{O} 2)=3.45 \AA)$ two monosynaptic basins, $\mathrm{V}(\mathrm{C} 3)$ and $\mathrm{V}(\mathrm{C} 7)$, appeared at the reacting centers. These basins are associated to the two centers responsible for the subsequent bond formation. Indeed, at the next point on the IRC (point 54) they have merged into a new disynaptic basin, $\mathrm{V}(\mathrm{C} 3, \mathrm{C} 7)$ confirming the $\mathrm{C} 3-\mathrm{C} 7$ bond formation.

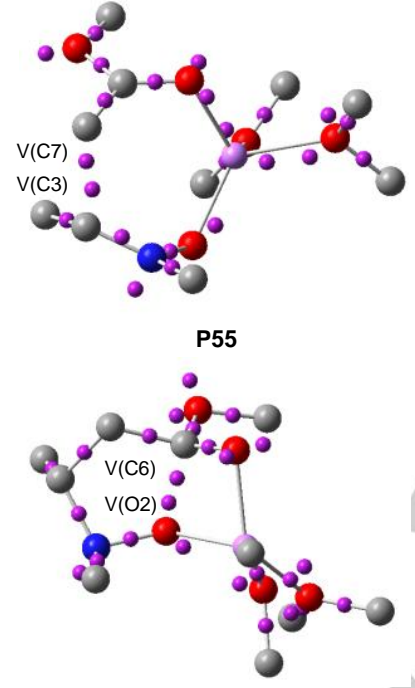

P21
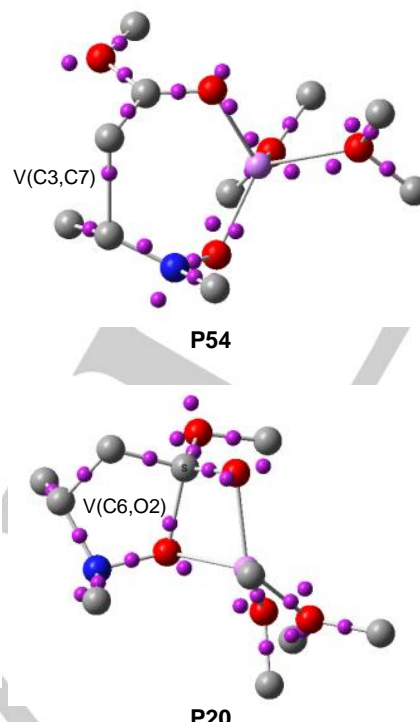

P20

Figure 7. Most relevant ELF attractors at selected points of the backwards IRCs of the stepwise reaction between nitrone NI and enolate ENa..

In the second step of the reaction, at TS4a (point 28 of the IRC) no monosynaptic basins appeared at the centers responsible of the formation of the second bond, $\mathrm{C} 6$ and $\mathrm{O} 2$. It is at point 21 when two monosynaptic basins, $\mathrm{V}(\mathrm{C} 6)$ and $\mathrm{V}(\mathrm{O} 2)$, appeared. At P20 they have merged into a disynaptic one confirming the formation of the new bond

The $\mathrm{NCl}$ analysis (Figure 8) for this reaction corroborates and complements the data observed during the ELF analysis. The starting complex, $\mathbf{C 1}$, shows a typical attractive interaction (green surface) between the $\pi$ systems corresponding to electron-rich enolate $\mathrm{C}=\mathrm{C}$ bond and the electron-poor nitrone $\mathrm{C}=\mathrm{N}$ bond. At the intermediate IN1a a clear non-covalent interaction is observed between $\mathrm{C} 6$ and $\mathrm{O} 2$ (blue surface) in agreement with a relatively short distance of $2.70 \AA$ and despite the formation of the second $\mathrm{C} 6-\mathrm{O} 2$ bond does not have started, as mentioned above. This observation is in agreement with that made for anionic stepwise [3+2] cycloadditions by Schelyer and co-workers who considered this sort of interaction as strictly electrostatic. ${ }^{[59]}$ More recently, we have also observed the same type of interactions in the stepwise cycloaddition between nitrone ylides and alkenes. ${ }^{[20 \mathrm{~b}]}$ For transition structures TS1a and TS4a the incipient formation of the new bonds is evidenced by the typical toroidal blue surfaces (Figure 8). At TS1a is evident that the interaction between $\mathrm{C} 6$ and $\mathrm{O} 2$ is negligible only being appreciable at the following stationary point IN1a.
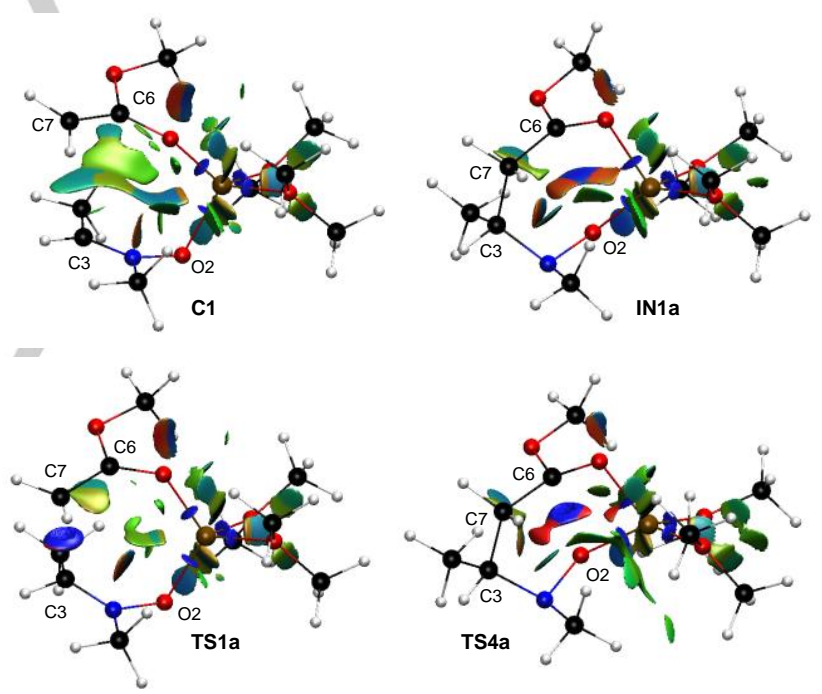

Figure 8. $\mathrm{NCl}$ analysis of relevant points $\mathrm{C} 1$, IN1a, TS1a and TS4a corresponding to the stepwise reaction between nitrone $\mathbf{N I}$ and enolate $\mathbf{E N a}$..

For the concerted reaction between nitrone $\mathbf{N I}$ and enolate ENc the attractor positions for points indicating bond formation are illustrated in Figure 9. For this reaction the ELF analysis of the attractors for $\mathbf{C} 3$ shows, in a similar way to $\mathbf{C 1}$, two disynaptic basins associated each one to the $\mathrm{C} 3=\mathrm{N} 1$ and $\mathrm{C} 6=\mathrm{C} 7$ double bonds of the nitrone and enolate moieties, respectively. At TS3b (point 60 of the IRC) the $\mathrm{C} 6-\mathrm{C} 7$ and $\mathrm{C} 3-\mathrm{N} 1$ bonding regions are characterized by $\mathrm{V}_{1}(\mathrm{C} 6, \mathrm{C} 7)$ and $\mathrm{V}_{1}(\mathrm{C} 3, \mathrm{~N} 1)$ disynaptic basins, which showed loss of electron density associated to the creation of the new $\mathrm{C} 3-\mathrm{C} 7$ bond. A monosynaptic basin $\mathrm{V}(\mathrm{C} 7)$ is observed and at P62 a new monosynaptic basin, V(C3), appears 
and the electron density of $\mathrm{V}(\mathrm{C} 7)$ increases. At the following point, P63, the two monosynaptic basins $\mathrm{V}(\mathrm{C} 3)$ and $\mathrm{V}(\mathrm{C} 7)$ have merged into a new disynaptic basin V(C3,C7). Notably, P62 and P63 associated with the first stage of the concerted process have similar electronic structures to P55 and P54 associated with the stepwise addition of ENa (see above). This indicates a similar arrangement in the formation of the first C-C bond, independently of the appearance of a further intermediate, whose stability (or existence) depends on electronic features that could stabilize such stationary point. Indeed, P63 resembles geometrically IN1a and the absence of $\mathrm{V}(\mathrm{C} 6, \mathrm{O} 2)$ attractor confirms that formation of the second bond has not begun. At P96 both $\mathrm{C} 3, \mathrm{C} 7$ distance $(1.54 \AA$ ) and the presence of $\mathrm{V}(\mathrm{C} 3, \mathrm{C} 7)$ attractor indicate the complete formation of the $\mathrm{C} 3-\mathrm{C} 7$ bond. At the same time, two monosynaptic basins, $\mathrm{V}(\mathrm{C} 6)$ and $\mathrm{V}(\mathrm{O} 2)$ appear. These basins merge, at P97, into a new disynaptic basin $(\mathrm{VC6}, \mathrm{O} 2)$ responsible of the formation of the second bond.

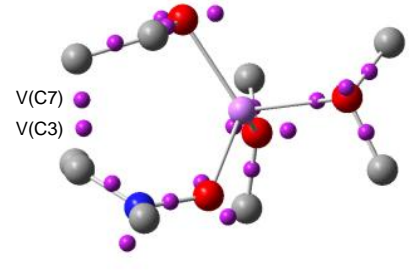

P63

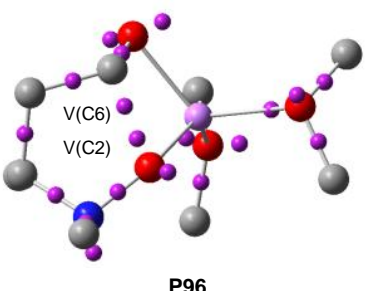

P96

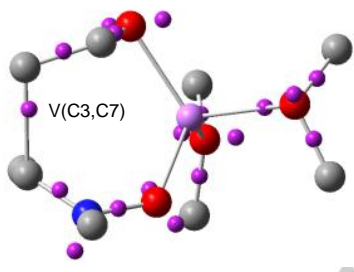

P63

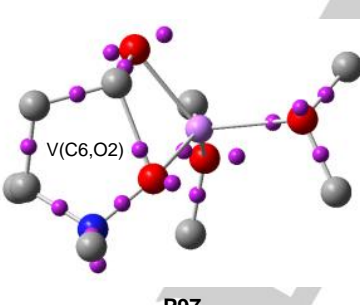

P97
Figure 9. Most relevant ELF attractors at selected points of the IRCs of the concerted reaction between nitrone $\mathrm{NI}$ and enolate ENc.

The $\mathrm{NCl}$ analysis of the starting complex $\mathbf{C 3}$, the transition structure TS3b and the two points, P63 and P97, in which the formation of the bonds has just taken place is illustrated in Figure 10. Similarly to $\mathbf{C 1}$, complex $\mathbf{C} 3$ shows an attractive interaction (green surface) between the $\pi$ systems corresponding to electron-rich enolate $\mathrm{C}=\mathrm{C}$ bond and the electron-poor nitrone $\mathrm{C}=\mathrm{N}$ bond. TS3b shows the interaction corresponding to the forming bond (toroidal blue surface). TS3b and P63 are very similar in their geometrical structure and both show a slight attractive interaction between $\mathrm{C} 6$ and $\mathrm{O} 2$ in a similar way (although weaker) to that observed for IN1 in the stepwise addition of ENa. Although an intermediate is not formed it is evident that the second bond (C6-O2) is not formed at this stage of the reaction, being completely formed only at P97.

The case of the reaction between nitrone $\mathbf{N I}$ and a-methyl enolate ENb can be considered as an intermediate situation which, however, opts by a stepwise mechanism due to unfavourable steric interactions still present between the methyl group of the a-enolate and the $\mathrm{N}$-methyl group. Both the ELF and $\mathrm{NCl}$ analyses are rather similar to those discussed above for the reaction with enolate ENa by just replacing the $\alpha$-methoxy group by the a-methyl group. The same applies for the nonpreferred concerted path which is rather similar to those found for enolate ENc by just replacing the $\alpha$-methyl group by an hydrogen atom (For the complete analyses of both concerted and stepwise pathways of the reaction between nitrone $\mathrm{NI}$ and enolate ENb see supporting information).
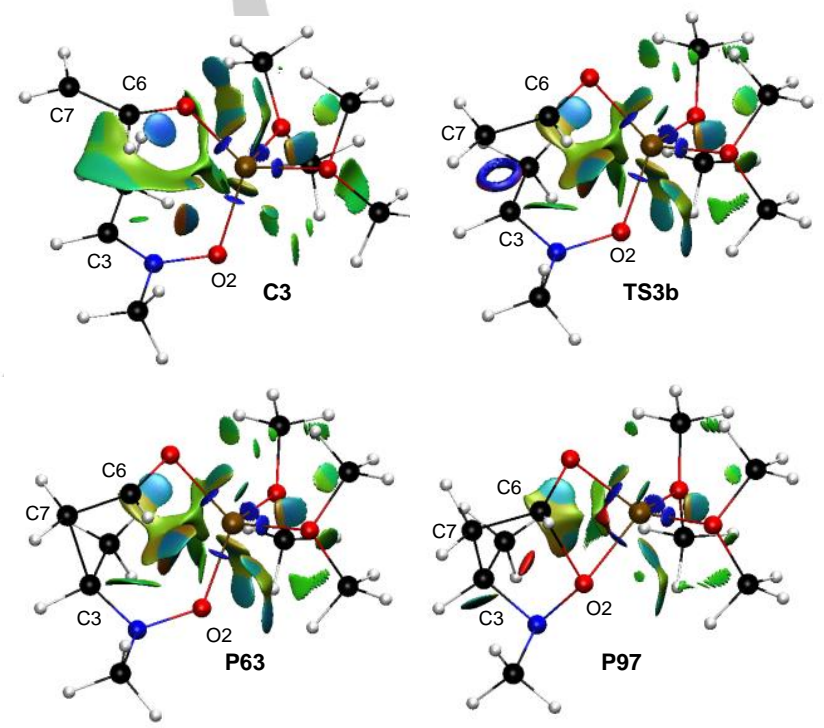

Figure 10. $\mathrm{NCl}$ analysis of relevant points C3, TS3a, P63 and P97 corresponding to the concerted reaction between nitrone $\mathrm{NI}$ and enolate ENc.

\section{Conclusions}

The addition of lithium enolates to nitrones takes place through the initial coordination of the nitrone to the lithium atom. Then, the intramolecular attack of the enolate moiety to the nitrone from initial complexes can take place by two different faces of the enolate. This causes that the $\alpha$-substituent of the enolate (OMe, Me or $\mathrm{H}$ ) can adopt inside and outside orientations with respect to the nitrone (Figure 11).

$$
\mathrm{Z}=\mathrm{OMe}, \mathrm{Me}
$$

outside stepwise<smiles>[Z]C(=O)O[Si]([SiH3])([SiH3])ON=C(C)C</smiles><smiles>Cc1cc2cc3c(cc(o1)n3C)o2</smiles>$$
\mathrm{Z}=\mathrm{H}
$$

inside one-step
Figure 11. Preferred approaches and change of mechanism for enolates derived from esters and ketones $(Z=O M e, M e)$, and aldehydes $(Z=H)$. (dashed lines indicate forming bonds). 
The inside position is sterically more demanding because of unfavorable interactions with the $\mathrm{N}$-methyl group of the nitrone and thus, the outside orientation is preferred. However, this approach involves a large separation between $\mathrm{C}$ and $\mathrm{O}$ atoms responsible of the formation of the second $\mathrm{C}-\mathrm{O}$ bond. This excessively long $\mathrm{C}-\mathrm{O}$ distance, minimizing attractive electrostatic interactions, avoids bonding between the interacting orbitals at the TS, and when an electron-donor substituent $(\mathrm{OMe})$ is present the reaction is stepwise because of the electronic stabilization of the intermediate (addition of $\mathbf{E N a ) . ~ I n ~ t h e ~}$ absence of $\alpha$-substituent the inside orientation is preferred (shortening the $\mathrm{C}-\mathrm{O}$ distance) and the reaction change its mechanism to concerted through a highly asynchronous transition structure (addition of ENc). The reaction with the $\alpha$ methyl enolate (ENb) represents an intermediate situation in which there is a substituent stabilizing in less extent the intermediate but still causing unfavorable steric interactions. Consequently, the concerted path appeared but is not the preferred one and the stepwise pathway shows a higher barrier $(8.3 \mathrm{kcal} / \mathrm{mol})$ than in the case of $\alpha$-methoxy enolate $(6.4$ $\mathrm{kcal} / \mathrm{mol})$.

The one-step processes are so asynchronous that they are more in agreement with a reaction which takes place in one single kinetic step but in two stages. This concept has been introduced by Domingo and co-workers ${ }^{[60]}$ and it is evidenced from the ELF analyses of the corresponding IRC calculations. From these analyses of the changes of bonding along the reaction coordinate we can conclude that, in the one-step processes, the formation of the second $\mathrm{C}-\mathrm{O}$ bond only begins when the first $\mathrm{C}-\mathrm{C}$ bond is completely formed. Consequently, these concerted highly asynchronous reactions do not follow a typical cyclic electron-reorganization as supported by the presence of hidden intermediates in the corresponding IRCs. As predicted by Rzepa and co-workers, ${ }^{[55 b]}$ stereoelectronic influence on the geometry induces the system to form a real intermediate.

In summary, while the reaction with a-unsusbtituted enolate ENc takes place along a one-step two-stage mechanism, the presence of a substituent at the $\alpha$-position in enolate (ENa and ENb) able to both lengthen the $\mathrm{C}-\mathrm{O}$ distance -avoiding orbital interactions- and stabilize the corresponding intermediate, switches the mechanism to a stepwise process.

\section{Acknowledgements}

This work was supported by the Ministerio de Economía y Competitividad (MINECO) and FEDER Program (Madrid, Spain, project CTQ2013-44367-C2-1-P) and the Gobierno de Aragón (Zaragoza, Spain. Bioorganic Chemistry Group. E-10). We acknowledge the Institute of Biocomputation and Physics of Complex Systems (BIFI) at the University of Zaragoza for computer time at clusters Terminus and Memento. D.R.-L. thanks the Spanish Ministry of Education (MEC) for a predoctoral grant (FPU program)..
Keywords: Mannich reaction $\cdot$ Nitrones $\cdot$ Enolates $\cdot \mathrm{NCl}$ analysis - ELF analysis

[1] a) N. Z. Burns and E. N. Jacobsen, Sci. Synth., Stereosel. Synth. 2011 2, 785-834; b) T. Akiyama, Compr. Chirality 2012, 6, 69-96; c) B. Karimi, D. Enders and E. Jafari, Synthesis 2013, 45, 2769-2812; d) S. Matsunaga, Compr. Chirality 2012, 4, 243-292; e) Z. Wang in Mannich reaction, John Wiley \& sons, New York, 2010, pp. 1820-1828; f) S. J. Greco, V. Lacerda, Jr. and R. Bezerra dos Santos, Aldrichimica Acta 2011, 44, 15-24; g) P. S. Bhadury and B.-A. Song, Curr. Org. Chem. 2010, 14, 1989-2006.

[2] a) H. Heaney in The Bimolecular Aromatic Mannich Reaction., Vol. 2 Eds.: B. M. Trost and I. Fleming), Pergamon Press, Oxford, 1991, p. 953; b) E. F. Kleinman in The Bimolecular Aliphatic Mannich and Related Reactions., Vol. 2 Eds.: B. M. Trost and I. Fleming), Pergamon Press, Oxford, 1991, p. 893; c) A. Córdova in Direct Catalytic Asymmetric Mannich Reactions., (Ed. G. Dyker), Wiley-VCH, Weinheim, 2005, pp. 359-370; d) A. Córdova and R. Rios in Direct Catalytic Asymmetric Mannich Reactions and Surroundings, (Ed. A. Ricci), Wiley-VCH, Weinheim, 2007, pp. 185-206; e) A. Cordova, Acc. Chem. Res. 2004, 37, 102-112.

[3] P. Merino and T. Tejero, Synlett 2011, 1965-1977.

[4] a) Y. Kita, F. Itoh, O. Tamura, Y. Y. Ke and Y. Tamura, Tetrahedron Lett. 1987, 28, 1431-1434; b) Y. Kita, F. Itoh, O. Tamura, Y. Y. Ke, T. Miki and Y. Tamura, Chem. Pharm. Bull. 1989, 37, 1446-1451.

[5] N. N. Saha, V. N. Desai and D. D. Dhavale, Tetrahedron 2001, 57, 39 46.

[6] a) P. Merino, S. Franco, N. Garces, F. L. Merchan and T. Tejero, Chem. Commun. 1998, 493-494; b) P. Merino, S. Franco, F. L. Merchan and T. Tejero, J. Org. Chem. 2000, 65, 5575-5589; c) P. Merino, E. M. del Alamo, M. Bona, S. Franco, F. L. Merchan, T. Tejero and O. Vieceli, Tetrahedron Lett. 2000, 41, 9239-9243; d) P. Merino, S. Franco, F. L. Merchan and T. Tejero, Tetrahedron Lett. 1998, 39, 6411-6414.

[7] P. Merino, P. Jimenez and T. Tejero, J. Org. Chem. 2006, 71, 4685 4688.

[8] a) J. Iqbal and S. K. Das, Enantiosel. Synth. $\beta$-Amino Acids (2nd Ed.) 2005, 241-260; b) T. Kawakami, H. Ohtake, H. Arakawa, T. Okachi, Y. Imada and S.-I. Murahashi, Bull. Chem. Soc. Jpn. 2000, 73, 2423-2444; c) H. Ohtake, Y. Imada and S.-I. Murahashi, J. Org. Chem. 1999, 64, 3790-3791; d) T. Kawakami, H. Ohtake, H. Arakawa, T. Okachi, Y. Imada and S.-I. Murahashi, Org. Lett. 1999, 1, 107-110; e) S. Jost, Y. Gimbert, A. E. Greene and F. Fotiadu, J. Org. Chem. 1997, 62, 66726677 ; f) S. Murahashi, Y. Imada, T. Kawakami, K. Harada, Y Yonemushi and N. Tomita, J. Am. Chem. Soc. 2002, 124, 2888-2889.

[9] P. Merino, Compt. Rend. Chim. 2005, 8, 775-788.

[10] T. Kawakami, H. Ohtake, H. Arakawa, T. Okachi, Y. Imada and S.-I. Murahashi, Chem. Lett. 1999, 795-796.

[11] P. Merino, S. Franco, P. Jimenez, T. Tejero and M. A. Chiacchio, Lett. Org. Chem. 2005, 2, 302-305.

[12] a) O. Tamura, K. Takeda, N. Mita, M. Sakamoto, I. Okamoto, N. Morita and H. Ishibashi, Org. Biomol. Chem. 2011, 9, 7411-7419; b) C. Qian and L. Wang, Tetrahedron 2000, 56, 7193-7197; c) Y. Kita, O. Tamura F. Itoh, H. Kishino, T. Miki, M. Kohno and Y. Tamura, Chem. Pharm. Bull. 1989, 37, 2002-2007.

[13] C. W. Downey, C. M. Dombrowski, E. N. Maxwell, C. L. Safran and O. A. Akomah, Eur. J. Org. Chem. 2013, 2013, 5716-5720.

[14] a) H. G. Aurich, M. Schmidt and T. Schwerzel, Chem. Ber. 1985, 118, 1086-1104; b) M. F. Schlecht, J. Chem. Soc., Chem. Commun. 1985 , 1239-1241.

[15] M. Cordaro, F. Risitano, A. Scala, A. Rescifina, U. Chiacchio and G. Grassi, J. Org. Chem. 2013, 78, 3972-3979.

[16] S. Tomoda, Y. Takeuchi and Y. Nomura, Chem. Lett. 1982, 1787-1790.

[17] P. Merino and J. A. Mates, ARKIVOC 2001, 12-30. 
[18] A. Milet, Y. Gimbert and A. E. Greene, J. Comput. Chem. 2006, 27, 157-162.

[19] L. R. Domingo, M. Arno, P. Merino and T. Tejero, Eur. J. Org. Chem. 2006, 3464-3472.

[20] a) P. Merino, V. Mannucci and T. Tejero, Tetrahedron 2005, 61, 33353347; b) P. Merino, T. Tejero and A. Diez Martinez, J. Org. Chem. 2014 79, 2189-2202; c) A. Diez-Martinez, T. Tejero and P. Merino, Tetrahedron Asymmetry 2010, 21, 2934-2943; d) P. Merino, T. Tejero and A. Diez-Martinez, J. Org. Chem. 2014, 79, 2189-2202; e) P. Merino J. Revuelta, T. Tejero, S. Cicchi and A. Goti, Eur. J. Org. Chem. 2004 776-782.

[21] a) I. Delso, E. Marca, V. Mannucci, T. Tejero, A. Goti and P. Merino, Chem. Eur. J. 2010, 16, 9910-9919; b) P. Merino and T. Tejero Tetrahedron 2001, 57, 8125-8128; c) P. Merino, A. Lanaspa, F. L. Merchan and T. Tejero, Tetrahedron: Asymmetry 1997, 8, 2381-2401.

[22] L. R. Domingo and J. Andres in General and Theoretial Aspects of the metal enolates, (Ed. J. Zabicky), Wiley, Chichester, 2009, pp. 1-79.

[23] M. J. Frisch, G. W. Trucks, H. B. Schlegel, G. E. Scuseria, M. A. Robb, J. R. Cheeseman, G. Scalmani, V. Barone, B. Mennucci, G. A. Petersson, H. Nakatsuji, M. Caricato, X. Li, H. P. Hratchian, A. F. Izmaylov, J. Bloino, G. Zheng, J. L. Sonnenberg, M. Hada, M. Ehara, K. Toyota, R. Fukuda, J. Hasegawa, M. Ishida, T. Nakajima, Y. Honda, O. Kitao, H. Nakai, T. Vreven, J. Montgomery, J. A., J. E. Peralta, F. Ogliaro, M. Bearpark, J. J. Heyd, E. Brothers, K. N. Kudin, V. N. Staroverov, R. Kobayashi, J. Normand, K. Raghavachari, A. Rendell, J. C. Burant, S. S. Iyengar, J. Tomasi, M. Cossi, N. Rega, J. M. Millam, M. Klene, J. E. Knox, J. B. Cross, V. Bakken, C. Adamo, J. Jaramillo, R Gomperts, R. E. Stratmann, O. Yazyev, A. J. Austin, R. Cammi, C. Pomelli, J. W. Ochterski, R. L. Martin, K. Morokuma, V. G. Zakrzewski, G. A. Voth, P. Salvador, J. J. Dannenberg, S. Dapprich, A. D. Daniels, Ö. Farkas, J. B. Foresman, J. V. Ortiz, J. Cioslowski and D. J. Fox in Gaussian 09. Revision D1., Vol. Gaussian, Inc., Wallingford CT, 2009.

[24] Y. Zhao and D. G. Truhlar, Acc. Chem. Res. 2008, 41, 157-167.

[25] a) T. H. Dunning Jr., J. Chem. Phys. 1989, 90, 1007-1023; b) R. A. Kendall, T. H. Dunning Jr. and R. J. Harris, J. Chem. Phys. 1992, 96 6796-6806; c) D. E. Woon and T. H. Dunning Jr., J. Chem. Phys. 1993, 98, 1358-1371.

[26] E. Papajak, J. Zheng, X. Xu, H. R. Leverentz and D. G. Truhlar, J. Chem. Theory Comput. 2011, 7, 3027-3034.

[27] a) D. Roca-Lopez, T. Tejero and P. Merino, J. Org. Chem. 2014, 79, 8358-8365; b) D. Roca-Lopez, V. Polo, T. Tejero and P. Merino, J. Org. Chem. 2015 in press. DOI: . 10.1021/acs.joc.5b00413.

[28] a) K. Fukui, J. Phys. Chem. 1970, 74, 4161-4163; b) K. Fukui, Acc. Chem. Res. 1981, 14, 363-368.

[29] (a) C. González and H. B. Schlegel, J. Phys. Chem. 1990, 94, 55235527. (b) C. González and H. B. Schlegel, J. Chem. Phys. 1991, 95 5853-5860.

[30] a) V. Barone, M. Cossi and J. Tomasi, J. Comput. Chem. 1998, 19, 404-417; b) E. Cances, B. Mennucci and J. Tomasi, J. Chem. Phys. 1997, 107, 3032-3041; c) M. Cossi, V. Barone, R. Cammi and J. Tomasi, Chem. Phys. Lett. 1996, 255, 327-335; d) M. Cossi, G. Scalmani, N. Rega and V. Barone, J. Chem. Phys. 2002, 117, 43-54; e) J. Tomasi and M. Persico, Chem. Rev. 1994, 94, 2027-2094.

[31] a) L. R. Domingo, S. Gil, R. Mestres and M. T. Picher, Tetrahedron 1996, 52, 11105-11112; b) L. R. Domingo, S. Gil, R. Mestres and M. T. Picher, Tetrahedron 1995, 51, 7207-7214

[32] a) Z. Rappoport and I. Marek in Chemistry of Organolithium Compounds, Vol. 1 (Ed. Z. Rappoport), Wiley, Chichester, 2004, p 1400; b) C. J. Hayes and N. S. Simpkins, Org. Biomol. Chem. 2013, 11, 8458-8462.

[33] a) E. R. Johnson, S. Keinan, P. Mori-Sanchez, J. Contreras-Garcia, A. J. Cohen and W. Yang, J. Am. Chem. Soc. 2010, 132, 6498-6506; b) J. R. Lane, J. Contreras-Garcia, J.-P. Piquemal, B. J. Miller and H. G. Kjaergaard, J. Chem. Theory Comput. 2013, 9, 3263-3266.
[34] J. Contreras-Garcia, E. R. Johnson, S. Keinan, R. Chaudret, J.-P Piquemal, D. N. Beratan and W. Yang, J. Chem. Theory Comput. 2011, 7, 625-632.

[35] W. Humphrey, A. Dalke and K. Schulten, J. Mol. Graph. 1996, 14.

[36] a) A. Savin, A. D. Becke, J. Flad, R. Nesper, H. Preuss and H. G. Vonschnering, Angew Chem. Int. Ed. 1991, 30, 409-412; b) A. Savin, R. Nesper, S. Wengert and T. F. Fassler, Angew. Chem. Int. Ed. 1997, 36

[37] a) A. Savin, B. Silvi and F. Colonna, Can. J. Chem. 1996, 74, 1088 1096; b) B. Silvi, J. Mol. Struct. 2002, 614, 3-10; c) B. Silvi and A. Savin, Nature 1994, 371, 683; d) R. Llusar, A. Beltran, J. Andres, S. Noury and B. Silvi, J. Comput. Chem. 1999, 20, 1517-1526; e) B. Silvi, I. Fourre and M. E. Alikhani, Monats. Chem. 2005, 136, 855-879; f) J. Andres, S. Berski, M. Feliz, R. Llusar, F. Sensato and B. Silvi, Compt. Rend. Chem. 2005, 8, 1400-1412.

[38] S. Noury, X. Krokidis, F. Fuster and B. Silvi, Comput. Chem. 1999, 23, 597-604.

[39] a) G. Bentabed-Ababsa, A. Derdour, T. Roisnel, J. A. Saez, P. Perez, E. Chamorro, L. R. Domingo and F. Mongin, J. Org. Chem. 2009, 74, 2120-2133; b) L. R. Domingo, E. Chamorro and P. Perez, J. Org. Chem. 2008, 73, 4615-4624; c) L. R. Domingo, E. Chamorro and P. Perez, Org. Biomol. Chem. 2010, 8, 5495-5504; d) L. R. Domingo, M. T. Picher and P. Arroyo, Eur. J. Org. Chem. 2006, 2570-2580; e) L. R. Domingo, M. T. Picher, P. Arroyo and J. A. Saez, J. Org. Chem. 2006, 71, 9319-9330.

[40] N. Gillet, R. Chaudret, J. Contreras-Garciia, W. Yang, B. Silvi and J.-P. Piquemal, J. Chem. Theory Comput. 2012, 8, 3993-3997.

[41] J. Andrés, S. Berski, J. Contreras-García and P. González-Navarrete, J. Phys. Chem. A 2014, 118, 1663-1672.

[42] C. Y. Legault, Université de Sherbrooke 2009, http://www.cylview.org

[43] P. Merino, S. Franco, N. Garces, F. L. Merchan and T. Tejero, Chem. Commun. 1998, 493-494.

[44] L. R. Liou, A. J. McNeil, A. Ramirez, G. E. S. Toombes, J. M. Gruver and D. B. Collum, J. Am. Chem. Soc. 130, 4859-4868.

[45] K. J. Kolonko, M. M. Biddle, I. A. Guzei and H. J. Reich, J. Am. Chem. Soc. 2009, 131, 11525-11534.

[46] A. Abbotto, A. Streitwieser and P. v. R. Schleyer, J. Am. Chem. Soc. 1997, 119, 11255-11268.

[47] L. M. Pratt, S. C. Nguyen and B. T. Thanh, J. Org. Chem. 2008, 73, 6086-6091.

[48] C. S. Pomelli, A. M. Bianucci, P. Crotti and L. Favero, J. Org. Chem 2004, 69, 150-157.

[49] D. Z.-R. Wang and A. Streitwieser, Can. J. Chem. 1999, 77, 654-658.

[50] P. Merino and T. Tejero, Tetrahedron 2001, 57, 8125-8128.

[51] G. Asensio, P. Aleman, J. Gil, L. R. Domingo and M. Medio-Simon, J. Org. Chem. 1998, 63, 9342-9347.

[52] G. K. S. Prakash, Z. Zhang, F. Wang, M. Rahm, C. Ni, M. Iuliucci, R. Haiges and G. A. Olah, Chem. Eur. J. 2014, 20, 831-838.

[53] a) K. Kobayashi, T. Matoba, S. Irisawa, A. Takanohashi, M. Tanmatsu, O. Morikawa and H. Konishi, Bull. Chem. Soc. Jpn. 2000, 73, 28052809 ; b) E. L. Kui, A. Kanazawa, J.-F. Poisson and S. Py, Tetrahedron Lett. 2013, 54, 5103-5105.

[54] a) N. Celebi-Olcum, Y.-H. Lam, E. Richmond, J. B. Ling, A. D. Smith and K. N. Houk, Angew. Chem. Int. Ed. 2011, 50, 11478-11482; b) E. Richmond, K. B. Ling, N. Dugue, t. B. Manton, N. Celebi-Olcum, Y.-H. Lam, S. Alsancak, A. M. Z. Slawin, K. N. Houk and A. D. Smith, Org. Biomol. Chem. 2015, 13, 1807-1817; c) L. R. Domingo, M. Arno and J. Andrés, J. Org. Chem. 1999, 64, 5867-5875; d) L. R. Domingo and J. Andres, J. Org. Chem. 2003, 68, 8662-8668; e) S. Berski, J. Andres, B. Silvi and L. R. Domingo, J. Phys. Chem. A 2006, 110, 13939-13947; f) V. Polo, J. Andres, R. Castillo, S. Berski and B. Silvi, Chem. Eur. J. 2004, 10, 5165-5172; g) S. Berski, A. J. Gordon and L. Z. Ciunik, J. Mol. Model. 2015, 21, 57-74; h) S. Berski and L. Z. Ciunik, Mol. Phys. 2015, 113, $765-781$ 
[55] a) E. Kraka and D. Cremer, Acc. Chem. Res. 2010, 43, 591-601; b) A. Armstrong, R. A. Boto, P. Dingwall, J. Contreras-Garcia, M. J. Harvey, N. J. Masona and H. S. Rzepa, Chem. Sci. 2014, 4, 2057-2071

[56] L. R. Domingo, RSC Adv. 2014, 4, 32415-32428.

[57] R. Chaudret, B. d. Courcy, J. Contreras-Garcia, E. Gloaguen, A. Zehnacker-Rentien, M. Mons and J.-P. Piquemal, Phys. Chem. Chem. Phys. 2014, 16, 9876-9891.

[58] M. Hennum, H. Fliegl, L.-L. Gundersen and O. Einsenstein, J. Org. Chem. 2014, 79, 2514-2521.

[59] F. Neumann, C. Lambert and P. v. R. Schleyer, J. Am. Chem. Soc. 1998, 120, 3357-3370.

[60] L. R. Domingo, J. A. Saez, R. J. Zaragoza and M. Arno, J. Org. Chem. 2008, 73, 8791-8799. 
Entry for the Table of Contents (Please choose one layout)

Layout 2:

\section{FULL PAPER}
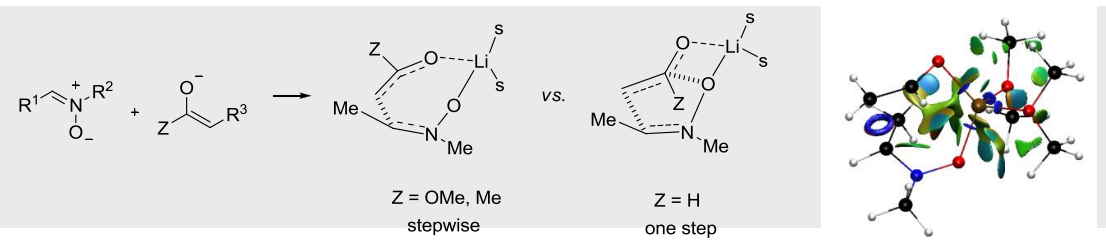

D. Roca-Lopez, V. Polo, T. Tejero and P. Merino*

Page No. - Page No.

Title

Depending on the type of enolate the reaction mechanism changes from one-step to stepwise 